\title{
De la sobriedad ética a la esperanza religiosa
}

\author{
MANUEL FRAIJÓ \\ UNED
}

La ética y la religion han vivido una relación tensa. Hasta el siglo XVIII, la ética vivió a la sombra de la religión; a partir de esa fecha la ética se independizó de la religión y amenazo con sofocarla. Este estudio se decanta por una relación menos conflictiva, en la que etica y religion aúnen sus esfuerzos a favor de la solidaridad, más allá incluso de las fronteras de la muerte.

\section{Una primera aproximación al tema}

En 1915 publicó el neokantiano Hermann Cohen su filosofía de la religión. ${ }^{1}$ Esta obra contiene un párrafo que zanja la secular contienda sobre la relación entre ética y religión con una contundencia poco habitual, por suerte, entre los filósofos. La cita de Cohen que, tal vez precisamente por su contundencia, figura en numerosas obras de filosofía de la religión, ${ }^{2}$ dice así: «Yo no he retrocedido ante la consecuencia metodológica de que la religión tiene que disolverse en la ética [...] Pues ¿qué mayor gloria para la religión que designar como su meta propia su disolución en la ética? [...] Quizás hasta podría ser éste el criterio más importante de cara al contenido de verdad de la religión: el de saber hasta qué punto es capaz de autodisolverse en la éticas. ${ }^{3}$

Desde luego - y en esto coincido con Cohen- la ética no es un mal destino. Pero sospecho que la religión no aceptaría de buen grado su autodisolución en ella. Considero más probable que la religión prefiera seguir siendo compañera de viaje de la ética. En realidad, las dos vienen de muy lejos. Juntas han recorrido largas etapas y han conocido parecidos vaivenes y zozobras. La ética no empieza allí donde termina la religión; a su vez, la religión no debe temer que la ética la suplante. La finalidad de estas páginas será mostrar que hay espacio para ambas. Tanto la ética como la religión pertenecen a lo que $K$. Nielsen denomina «términos teóricamente cargados». Tomando de Nielsen sólo la expresión y no el sentido en el que él la utiliza, yo diría que su principal "carga" consiste en que, desde siempre, la ética y la religión intentaron presentar un cuadro inteligible del mundo. Ni la ética ni la religión tienen vocación sectorial. Ambas miran hacia horizontes amplios. Las creencias y prácticas de los humanos no toleran el aislamiento. Ya advirtió Dilthey que aislar es empobrecer. Nin- 
guna ética es separable del pensamiento filosófico global en el que se inserta; y también la religión ama la interconexión y agradece la ayuda que le brinden otros compañeros de viaje. Ni la ética trata sólo de la rectitud de las acciones humanas, ni la religión se refiere únicamente a la relación del hombre con Dios. Ambas apuntan hacia una inteligibilidad más global, más abarcadora. Ambas tienen que ver con lo que Fichte, en un escrito de divulgación, llamó "Die Bestimmung des Menschen». Es ese «destino» o esa "mision" del hombre lo que siempre está en juego en la ética y la religión.

Fichte pensaba que el hombre no puede estar destinado a ser un mero "portador de fardos". Como Kant, Fichte auguraba al hombre una paz perpetua. Se resistía a que la vida consista en ucomer y beber para volver luego a tener hambre y sed y poder de nuevo comer y beber hasta que se abra ante mis pies el sepulcro y me trague y ser yo mismo alimento que brota del suelo». No se resignaba a que todo gire en torno a «engendrar seres semejantes para que también ellos coman y beban y mueran y dejen detrás de sí otros seres que hagan lo mismo que yo hicen. ${ }^{4}$

No es necesario acumular trazados patéticos de la vida como el que nos ofrece Fichte. Pero sería fácil hacerlo. Mircea Eliade evoca el «terror de la historia". Y Bloch se rebelaba, "por dignidad personal", contra la sangrante evidencia de que el hombre «acaba igual que el ganado».

La ética y la religión contemplaron siempre con honda inquietud este cuadro. A ambas les es connatural la falta de resignación. Nunca se avinieron bien con el perecimiento definitivo del ser humano. Se atrevieron a poner sobre el tapete frágiles esperanzas que nunca lograron fundamentar plenamente. Nunca renunciaron a mantener encendida la chispa de la esperanza, incluso para los muertos (W. Benjamin).

Pendientes siempre del "qué debemos hacer» y del «qué nos cabe esperar», la ética y la religión son dos saberes melancólicos que nunca alcanzan su meta. A ambas les acompaña esa "melancolía de la plenitud" que evocó Bloch.

Tradicionalmente, animados tal vez por el "divide y vencerás», hemos responsabilizado a la ética del «qué debemos hacer» y hemos reservado a la religión la tarea de administrar el "qué nos cabe esperar». Es muy probable que tal división de competencias no sea pertinente. Aunque tal vez con desigual intensidad, tanto la ética como la religión tienen que servir en ambos frentes. Ambas buscan, con tenacidad, el sentido de la vida. Ambas crean esperanza. Es posible incluso que el término "esperanza» las englobe a ambas. Quien se atreve a pronunciar el formidable y equívoco término «esperanza» - «el sueño de un vigilante» la llamó Aristóteles- está hablando implícitamente de ética y religión.

Esto sí: el ritmo de aproximación es diverso. El caminar de la ética hacia la esperanza es sobrio y zigzagueante; la religión, en cambio, puede, 
aunque no está obligada a ello, permitirse algún que otro acelerón. Casi siempre estamos dispuestos a ser indulgentes con sus alegres escapadas. No nos sabe mal que alguien ofrezca mucho. Solemos pensar que «los hechos" se encargan de poner a cada uno en su sitio. Y así es. Los hechos, la vida, el dolor y la muerte hacen palidecer las generosas ofertas de esperanza de las religiones. Su esperanza se torna, como dice Bloch, una esperanza "enlutada». A pesar de todo, en temas de esperanza, el discurso religioso es más asertivo que el ético.

Con todo -es necesario decirlo- también las religiones han aprendido a enmudecer. En realidad, el silencio nunca les fue ajeno, aunque no lo practicaran en la medida adecuada. Pero, el siglo que termina, con su inmensa barbarie, ha atemperado, no sé si definitivamente, certezas y asertividades. También la religion, aunque en menor medida que la ética, se ha familiarizado con la sobriedad. Sin renunciar a sus promesas, las inscribe en un marco humilde y modesto.

La ética y la religión tienen una misma urgencia: la solidaridad. Ése es su gran punto de encuentro. Es ahí donde pueden y deben prestarse mutua ayuda. Una ayuda que J. Sádaba evoca en estos términos: «No obstante, podría darse, al menos como interesada posibjilidad, la mediación de la religión para curar las heridas de una moral siempre sangrando».5

Pero, antes de continuar por este camino, es conveniente que nos ocupemos de algunos avatares históricos. Vamos, en el siguiente apartado, a repasar algunos hitos de la relación entre ética y religión. Posteriormente, en el tercer apartado, retomaremos la reflexión sistemática.

Entre paréntesis: no distinguiré, en mi discurso, entre ética y moral. Tal distinción me exigiría una disciplina que entorpecería el hilo de la exposición. También empleo el término "religión" en su acepción general, sin los matices que serían necesarios.

\section{Hitos de una relacion}

La relación entre ética y religión ha conocido una historia agitada. No voy a seguir en detalle todas esas peripecias. Su historia la escribio, hace más de treinta años, José Luis L. Aranguren. ${ }^{\top}$ En nuestros días ha vuelto a recordarla, en lúcida y apretada síntesis, Juan Martín Velasco. ${ }^{7}$ Ambos dedican amplia atención a las cinco antinomias que, según N. Hartmann, ${ }^{8}$ separan el ethos moral de la actitud religiosa. ${ }^{9}$

Aunque sospecho que ningún discurso ético se haría hoy eco, sin más, de tales antinomias, prefiero recordarlas antes de pasar a los dos estadios en los que sitúo la relación entre ética y religión.

La primera antinomia afirma, en un alarde de simplificación, que la ética se refiere al más acá y la religión al más allá. Hartmann piensa que la auténtica religion no otorga valor a lo intramundano. Naturalmente 
encuentra amplio apoyo en la historia del cristianismo. Recuerda que, con frecuencia, éste inculcó la fuga mundi y el desprecio de las realidades terrenas. En cambio, la ética es plenamente de este mundo. Los valores que apadrina se realizan todos en el marco de la más estricta inmanencia.

La segunda antinomia destaca que la ética es asunto del hombre, mientras que la religión se refiere a Dios. La actitud religiosa se orienta a Dios. Para el hombre religioso ś́lo es "bueno» lo que Dios quiere, lo que Dios manda. En cambio, el ethos moral nada sabe de esa instancia superior.

La tercera antinomia está en relación con las anteriores. La ética es una instancia autónoma. En cambio, el hombre religioso es heterónomo y dependiente. Y aquí no valen las componendas: ni la ética puede renunciar a su autonomía, ni el hombre religioso puede poner en juego su permanente referencia a Dios. Para la ética no existe autoridad privilegiada ni mandamientos divinos. La religión, en cambio, está pendiente de las estrellas, es decir, de instancias y preceptos que caen del cielo.

La cuarta antinomia se refiere al abismo existente entre libertad y providencia. La ética se basa en la libertad, la religión en la providencia. Hartmann entiende la providencia como determinismo. No queda, pues, espacio para la autodeterminación humana. La providencia elimina la libertad. Y, si se afirma la libertad, se elimina la providencia.

La quinta antinomia, por fin, afirma que la ética no conoce la redención, mientras que la religión vive de ella. El hombre religioso espera la redención del pecado. Confía en que Dios le libere de él. Algo que la ética no puede comprender. Para ella, la culpa es inseparable del culpable. Es «imposible» que alguien nos libere de la culpa. Pero, además, es moralmente rechazable, ya que el hombre se convertiria en dependiente de quien le redíme. La redención es, de nuevo, un canto a la heteronomía. Para la religión, en cambio, la redención es el supremo valor y el más ardiente anhelo.

No evoco estas antinomias por simple prurito histórico. Lo hago, más bien, porque considero que, con menor énfasis y sin tanta contundencia, han enturbiado y continúan enturbiando la relación entre ética y religión. Con su alegato, Hartmann quiso poner de relieve que la ética y la religión son dos magnitudes irreconciliables. Los problemas que él abordó, sin ser naturalmente el primero en afrontarlos, siguen reclamando estudio y reflexión.

La dificultad para conciliar ética y religión es real. La historia muestra que, con frecuencia, anduvieron a codazos. Hubo épocas en las que la religión sofocó a la ética. Y también surgieron intentos de reducir la religión a la ética. Es lo que ahora me propongo mostrar brevemente. No hay afán ni posibilidad de exhaustividad. 


\section{a) La ética, a la sombra de la religión}

No me refiero a la posibilidad, apuntada por G. Mensching, ${ }^{10}$ de que existan algunas religiones primitivas que carezcan de ética. Martín Velasco lo considera improbable. " Aranguren, en cambio, escribe: "La actitud religiosa, separada de la moral, se ha dado y se da en las "inmorales" religiones primitivas, que exigen, por ejemplo, sacrificios humanos o la comisión de actos deshonestos».12 Pero, el mismo Aranguren observa que eesos actos reprobables son ordenados y cometidos $s u b$ ratione bonin. Esos sacrificios humanos son «expresion injusta del justo reconocimiento del sefforí de Dios sobre la vida y sobre todos los seres ${ }^{13}$ Probablemente no es necesario negar un cierto atisbo ético, aunque rudimentario, a las religiones primitivas, incluso a las que Aranguren llama "inmorales".

Pero, como acabo de señalar, no pretendo adentrarme en ese tema. Bajo el título "la ética, a la sombra de la religión» me refiero a un hecho bien conocido: la ética no se independizó de la religión hasta los albores del siglo XVIII. Y, probablemente, esta secularización de los valores éticos se circunscribe a lo que solemos denominar "el mundo occidental». Siguen existiendo sociedades, incluso continentes, donde las religiones siguen determinando los valores. De ahí la necesidad de contar con la colaboración de las religiones a la hora de configurar proyectos éticos. ${ }^{14}$ En muchos lugares, esos proyectos nacerán muertos si no cuentan con la anuencia de las religiones. Por otra parte, en lo referente a la ética, las religiones se sienten desbordadas. Pongamos un ejemplo referido al cristianismo: cuando nació Jesús de Nazaret había unos doscientos millones de hombres sobre la tierra. Hoy nos aproximamos a los seis mil millones. De aquellos doscientos millones, Jesús se dirigió sólo a una pequeña parte: a los hijos de la casa de Israel. Esto significa que el mensaje de Jesús, pensado para pocos y, probablemente, para poco tiempo - se contaba con el fin inminente del mundo- se ve ahora confrontado con los retos de un mundo extremadamente variado y complejo.

Aun así, el cristianismo ha configurado, casi en solitario y durante muchos siglos, los valores morales de Occidente. Por cierto: el resultado no parece muy halagador. Pero tampoco sabemos dónde estariamos si nos hubiesen empujado otras instancias.

Otras religiones jugaron, en sus diferentes culturas, un papel parecido al del cristianismo. También ellas ejercieron y siguen ejerciendo una especie de monopolio en la determinación de los valores. Y tampoco a ellas se les escatiman reproches. Un ejemplo: con frecuencia se hace responsable de la pobreza de la India a la pasividad de sus religiones místicas.

Hans Küng tiene razón: «Sin duda, durante milenios de historia, las religiones fueron los sistemas de orientación que servian de base a una determinada moral, la legitimaban, motivaban y hasta sancionaban con 
penas» ${ }^{15}$ Ha sido, claramente, el caso del cristianismo en nuestro ámbito cultural. Y, si hoy observamos que muchos hombres vuelven su mirada hacia una "ética profana", es, piensa $P$. Tillich, porque el cristianismo ha predicado un "moralismo inmisericorde». ${ }^{16}$

De suyo, en el tema que nos ocupa, $\mathrm{P}$. Tillich tenía las cosas claras: «Dado que la moralidad es, por su propia esencia, religiosa, y la religión es esencialmente moral, se sigue que son independientes entre sí y que no pueden suplantarse mutuamentes. ${ }^{17}$ Pero Tillich cae de lleno bajo el epígrafe de este apartado. En efecto: según Tillich, el imperativo moral posee una dimensión religiosa. Es más: también los preceptos morales tienen origen religioso. Y, por supuesto, el elemento religioso está presente en las motivaciones morales. De esta forma, aunque la moralidad no depende, en sentido estricto, de ninguna religión concreta, es, por su propia esencia, religiosa. Sólo así se explica el carácter absoluto del imperativo moral. Además: la norma suprema del imperativo moral es el amor, entendido como agape. Y no hay agape sin una fundamentación trascendente. Estamos ante un género de amor que. "trasciende las posibilidades finitas del hombre». Tillich cita, en este contexto, el himno de san Pablo al amor (1 Co 13). Y recalca que la justicia, tema ético por excelencia, difícilmente encontrará nunca mejores valedores que los que tuvo en los profetas del Antiguo Testamento. ${ }^{18}$

Pero, quienes más decididamente situaron la religión por encima de la ética fueron los grandes genios religiosos. Aranguren, que ha dedicado a Lutero páginas tan logradas, insiste en el rechazo luterano de la moral como camino de justificación ante Dios. ${ }^{19}$ En efecto: situado en una época que busca desesperadamente la salvación, Lutero ensaya escrupulosamente el itinerario moral. Pero, la rigurosa observancia de la ley sólo logra aumentar su desesperación interior. $Y$ es entonces cuando percibe que no ha entendido el cristianismo. La "experiencia de la torres le revela que su salvación no está en sus manos ni será consecuencia de su esfuerzo moral. De pronto, se le amontona la luz y descubre algo que Pablo había escrito muchos siglos antes: «Estamos salvados. Operemos nuestra salvación». Desde entonces, Lutero vive la tensión entre la Ley y el Evangelio. Es decir: intuye que, después de la muerte de Cristo, la salvación no puede discurrir por los mismos cauces que antes de ella. Si así fuese, si el esfuerzo moral continúa siendo lo decisivo para la salvación, aquella muerte habría sido "en vano", no habría tenido consecuencias. Lutero comprende que aquella muerte lo ha cambiado todo. Ahora, lo crucial será el Evangelio, la buena nueva de que estamos salvados. El otro polo de la tensión, la Ley, continúa vigente -operemos nuestra salvación - pero se la contempla con paz y distensión, sin el agarrotamiento y la urgencia precipitada de quien todo lo cifra en su minucioso cumplimiento.

Éste fue el "descubrimiento" de Lutero. El Reformador no pensó nun- 
ca en abolir la moral, pero la privó del honor de ser la última y definitiva instancia.

Éste fue también el caso paradigmático de Kierkegaard, un cristiano, por lo demás, muy cercano al talante de Lutero. También él se dejó la ética en el camino. Llegó a hablar de su «suspensión». Ése fue el resultado final de su teoría de los «tres estadios».20

El hombre que vive en el primer estadio, el estético, sólo busca el goce inmediato de las cosas. Kierkegaard afirma que este hombre vive uen el sótano de su propio edificio». Disperso y eternamente insatisfecho, andará a la deriva y acabará en la desesperación. Sólo existe un camino para liberarse de la desesperación: dando el salto al estadio ético. Este estadio genera lo que Kierkegaard llama «el héroe trágico». En él impera la fidelidad a las obligaciones morales.

Pero, también sobre este estadio se cierne una amenaza: la autosuficiencia moral que terminará despertando la conciencia de pecado. Quien no desee vivir con el aguijón del pecado deberá dar el salto al tercer estadio, al religioso. $\mathrm{Y}$ en este estadio, en el que se entra en relación directa con Dios, palidece la ética. Es más: Dios puede exigir su total «suspensión». Kierkegaard hace una lectura literal del capítulo 22 del Génesis en el que Dios pide a Abraham que le sacrifique a su único hijo Isaac.

Concluyo aquí esta evocación selectiva de la primacía de la religión sobre la ética. Dos son los motivos que la han determinado: 1) La posición hegemónica del cristianismo en Occidente. Ya se quejaba Nietzsche de que el cristianismo era la matriz axiológica de nuestra cultura. Y P. Ricoeur reconoce que la fe cristiana es el trasfondo de los grandes proyectos éticos del pensamiento occidental. Tal vez por todo ello escribió Kolakowski; "Ser enteramente no cristiano equivaldría a no pertenecer a esta cultura». 2) $\mathrm{La}$ intensidad religiosa con que determinados cristianos vivieron su fe. Y pienso que no deberíamos ser cicateros con estos hombres. La tensión interior, el temor y temblor que sintió Kierkegaard al adentrarse en el estadio religioso merece todos mis respetos. Encuentro comprensible que, desde tan elevadas cumbres, se contemplen con cierto distanciamiento los humildes afanes de la ética. A los no geniales siempre nos será difícil juzgar lo genial. Renuncio, pues, a "reñir» a Lutero, Kierkegaard, san Agustín y a cuantos vivieron la experiencia religiosa con intensidades para mí desconocidas.

b) La religion, a la sombra de la ética

A veces, el péndulo osciló en sentido opuesto: la ética parecía engullir a la religión. Las primeras tentativas causaron gran revuelo. Fichte se vio obligado a renunciar a su cátedra de Jena. Se le acusaba, precisamente, de diluir la religión en la moral y, por tanto, de deslizarse hacia el ateísmo. 
Los ánimos se enconaron tanto que ni siquiera Goethe se atrevió a defender a Fichte. Y es que, en su escrito Sobre el fundamento de nuestra fe en un gobiemo divino del mundo, Fichte había aventurado afirmaciones como ésta: «Este orden moral vivo y efectivo de las cosas es Dios mismo; ni tenemos necesidad de otro Dios ni podemos concebirlow. ${ }^{21}$ Probablemente, una recta comprensión del sistema filosófico fichteano hubiese hecho superflua la polémica. Pero tal comprensión no estaba al alcance de todos.

La verdad es que no resulta difícil comprender esta tendencia. En Europa, la religión ha mostrado suficientemente toda su carga de ambivalencia e incluso de peligrosidad. Llegó un momento en que Europa tuvo que prescindir de la religión para no sucumbir. Las guerras de religión amenazaban con devastarlo todo. Y la Iglesia creó una Inquisición que prendía fuego a pensadores y disidentes. La religión se convirtió en un penoso capítulo de ambigüedades y contradicciones. Fue ella quien labró su propia secularización.

Es natural que se alzasen voces que deseaban salvar lo esencial. Y lo esencial no era la religión, sino la ética. Sin religión se puede vivir; sin ética no. Gráficamente afirmaba B. Russell que, cuando subía a un avión, se interesaba más por la ética del piloto que por su religión. Sin unos mínimos éticos, la convivencia se toma imposible. ${ }^{22}$ En cambio, el factor religioso no parece determinante. Es algo excedente. Sin él todo parece seguir funcionando. En cualquier tierra que pisemos, por lejana y exótica que sea, se nos exigirá el estricto cumplimiento de determinadas normas éticas. Nadie, en cambio, se interesará por nuestro credo religioso. No se nos pedirá que adoptemos la religión del país que visitamos; en cambio, no se nos eximirá de la observancia moral. Con una particularidad importante: mientras el abanico religioso admite un gran colorido - existen muchas religiones- la ética conoce la restricción. Con otras palabras: se puede optar por cualquiera de las múltiples religiones existentes, pero no es posible optar por matar a un semejante. En la ética disponemos de un acervo común, trabajosamente conquistado. No existe, en cambio, dicho acervo en el ámbito de las creencias religiosas.

Reflexiones de este género -imagino- condujeron a la cultura occidental a decantarse por lo más urgente: la ética. No es que se pensase que el factor religioso carecía de trascendencia. Prueba de ello es que los intentos por eliminarlo fueron fugaces y poco exitosos. Pero se concluyó que, dadas sus múltiples variantes y ambiguo pasado, no se le podía encomendar lo esencial: la organización de la convivencia humana.

Occidente se hizo consciente, además, de una serie de datos que avalaban la prevalencia de la ética sobre la religión. Se constató que personas sin creencias religiosas eran portadoras de grandes valores morales. $Y$ no se dejó de observar que, por el contrario, la adhesión a una determinada religión no siempre erá garantía de probidad moral. Se consideró, además, 
que el despertar de la Ilustración europea sacudía ancestrales creencias en la existencia de Dios. Dios se tornó, a lo sumo, un postulado, un desideratum. Y se pensó que no era bueno que las convicciones éticas dependiesen de $\tan$ frágil posibilidad. Se ensayó así una ética autónoma, libre de ataduras religiosas. Además: esta ética, ajena a sanciones y premios de ultratumba, aparecía como más limpia, más pura, más desinteresada.

Se aterrizó así en un novum relevante: es preferible que la moral carezca de fundamentación a que se fundamente sobre un absoluto religioso. Se convivia mejor con lo indeterminado que con lo absolutamente determinado. Y se llegó incluso a rechazar la creencia en Dios por motivos morales. Ateniéndose escrupulosamente a la imagen de Dios transmitida por el cristianismo -un Dios todopoderoso, bueno y omnisciente- comenzaron a abrirse paso las inevitables preguntas de siempre: cpor qué no impide ese buen Dios los males que aquejan al mundo? Algunos, como A. Camus, mostraron, con impresionante honestidad, su disconformidad con un mundo «en el que los niños sufren y mueren». Y se decidieron, de nuevo como Camus, a prescindir de Dios y «reducir el número de niños torturadosm. ${ }^{23}$ Con un vigor y dramatismo, para el que hoy apenas nos quedan energías, Camus vino a proponer que el hombre se establezca por cuenta propia y deje de esperar la ayuda que nunca llega. Su alegato impactó a muchos. ${ }^{24}$

El pertinaz silencio de Dios frente al dolor y abandono de los humanos y el fracaso del cristianismo en la creación e implantación de valores genuinamente éticos han rematado la faena: la ética se apresta a recorrer su camino en solitario, libre de dictados heterónomos. El precio a pagar tiene un nombre: no hay fundamentación trascendente. La divisa es: «Trascender sin Trascendencia». La acuñó Bloch, pero ha pasado a ser una especie de bien común. De la religión se toma, simplemente, lo aprovechable. No hay inconveniente en heredar, pero selectivamente. Si la religión contiene inconformismo y rebelión, se asimila su impulso. Pero sólo son posibles identificaciones parciales. Nada de adhesiones totales. Se seleccionan aquellos estratos de la tradición bíblica que nos ayuden a encarar la adversidad, a caminar cerguidos», a transformar el mundo en un ulaboratorium possibilis salutis». ${ }^{25}$ Pero ninguna herencia debe ahorrar el propio esfuerzo. La creación de valores es cosa nuestra. La obligación moral, también. En este ámbito no es posible la delegación.

$\mathrm{Y}$, arrojado el lastre religioso, la vida puede quedar, como en el caso de $B$. Russell, alimentada por estas atres simples, pero poderosas pasiones: anhelo de amor, afán de conocimiento y una insoportable sim-patía con el dolor de la humanidads. ${ }^{26}$ No es, ciertamente, un mal bagaje.

No sería lícito concluir este apartado sin mencionar, aunque sólo sea brevemente, a F. Nietzsche. Nadie como él se rebeló contra una determinada genealogía de la moral: la que procede del cristianismo. En Nietzsche 
no existe esa voluntad de herencia que Kant tanto ensalzó. Las «viejas tablas" deben ser destruidas, Lo que hasta ahora se ha llamado virtud es «cobardía», "debilidad». Gráficamente escribe: "Aquí nos ayudamos unos a otros, aquí, hasta cierto punto, cada uno es un enfermero y cada uno es un enfermon. ${ }^{27} \mathrm{El}$ ideal es el hombre fuerte del Renacimiento. La gran acusación nietzscheana contra la Modernidad es que ésta aceptó la moral cristiana. Incluso los ilustrados, que combatieron la idea de Dios, admitieron esta moral. Hasta los partidos políticos de izquierdas cayeron en la trampa.

Nietzsche acusa al cristianismo de luchar contra los instintos fundamentales, de tomar partido por lo débil, bajo y malogrado, de corromper a Pascal, de negar la vida, de impulsar la decadencia de la especie..$^{28} \mathrm{El}$ cristianismo es para él "la única gran maldición», la "única inmortal mancha deshonrosa de la humanidad». ${ }^{29}$ Nietzsche representa, pues, el intento más pertinaz de abolir la religión en aras de su particular ética.

Pero, probablemente, el último esfuerzo importante por reducir el discurso religioso al discurso moral es consecuencia del impacto de la filosofía analítica. Dicha filosofía había negado el carácter cognoscitivo de los enunciados religiosos. Se trataba de asertos que no podian ser verificados ni falsados. Se organizó entonces una estrategia de salvamento: los enunciados religiosos - se argument $\delta$ - aunque no afirmen nada, "expresan» algo. Fue, por ejemplo, el caso de R.B. Braithwaite. Defendió que las proposiciones religiosas carecen de contenido empírico, pero, apoyado en Wittgenstein, afirmo: "Si tales proposiciones tienen un uso, tienen también un significado». ${ }^{30} \mathrm{Y}$ ese significado se reduce a expresar el compromiso ético del creyente. La proposición religiosa "Dios es amor" sólo significa, para Braithwaite, que el creyente quiere seguir un estilo de vida caracterizado por el amor. Lo importante es que las proposiciones religiosas ayuden a realizar el género de vida elegido.

Algo parecido sostiene R. Hepburn. Según él, las afirmaciones religiosas sirven para reforzar la moralidad por medio del recurso a las parábolas. Pero insiste en que "tampoco tiene gran importancia que la historia (la parábola) sea históricamente verdadera. Puede desempeñar su misión igualmente bien, aunque sea ficticia; a veces, incluso la desempeña mejor». ${ }^{31}$

Por último: incluso algunos teólogos cristianos sucumbieron a la tentación de diluir el cristianismo en la ética. Ocurrió en la teología liberal protestante, sobre todo en la figura de A. Ritschl. ${ }^{32}$ Para esta teología, Jesús de Nazaret se convirtió, casi exclusivamente. en un modelo de vida que encarnaba las virtudes liberales de la época. Más que con Dios, el cristianismo tenía que ver con la moralidad, la cultura y las cosmovisiones del momento. La dimensión escatológica de lo cristiano fue reemplazada por la dimensión ética. El gran tema era: ¿cómo se debe relacionar el cristiano 
con el trabajo, la cultura, los bienes materiales, y un largo etcétera? A. von Harnack, por ejemplo, no tenía reparos en vincular la cosmovisión cristiana con la de Goethe. ${ }^{33}$

Se alumbro, así, una teología lisa y bien avenida con la mentalidad burguesa imperante. La palabra mágica era «reconciliacion». De hecho, la obra más importante de Ritschl, publicada entre 1870 y 1874, llevaba por título Rechtfertigung und Versöhnung. Pero, todo el énfasis se ponía en el término Versöhnung. Se trataba de reconciliar el reino de Dios con el ideal humano. El cristianismo no debía ser un factor distorsionante. Debía insertarse sin violencia en la dinámica de lo humano.

$Y$, en verdad, la reconciliación no pudo ser más completa: la noche del 4 de agosto de 1914, el gran Harnack redactaba la proclama bélica del Kaiser Guillermo II. Y, unos días más tarde, firmaba, con otros 92 intelectuales, el llamado Manifiesto de los intelectuales que se adheria públicamente a la política belicista del Kaiser. No se podía pedir mayor adaptación del cristianismo a la realidad imperante.

Muchos años después, $\mathrm{K}$. Barth recordará aquel amargo despertar de comienzos de agosto de 1914. De golpe se encontró con que la casi totalidad de sus venerados maestros de teología habían estampado su firma al pie del Manifiesto. Alli estaban, además de Harnack, W. Hermann, R. Seeberg, A. Schlatter y otros. Por cierto: también firmaban los filosofos W. Windelband, R. Eucken y W. Wundt.

Barth lo comprendió todo de golpe: aquella mañana había muerto la teología liberal. Urgía levantar el edificio teológico sobre bases más firmes. Dios no podía ser, sin más, la confirmación de los intereses humanos. No eran lícitas las precipitadas síntesis entre lo divino y lo humano que había trenzado la teología liberal. Dios era también crisis, "pared de fuego impenetrable", "grito de alarma" "señal de fuego». Dios es "cualitativamente diferente del hombre». Fue así como, sobre las ruinas de la teología liberal, comenzó a alzarse una nueva teología a la que se dio en llamar «dialecticas. ${ }^{34}$

Llegamos, así, al final de este apartado. Sólo se trataba de recordar unos cuantos episodios de una historia apasionante: la de la emancipación de la ética de la tutela religiosa. Ahora nos queda probablemente lo más difícil: detectar que la ética y la religión, independizadas la una de la otra, tienen una tarea común. A ambas les interesa que la esperanza de los humanos no se frustre por completo.

\section{La esperanza, un reto para la ética y la religión}

Aranguren, un hombre que ha dedicado su esfuerzo intelectual, casi por igual, a la ética y la religión, confiesa que «hay capítulos de la ética que no sabría cómo abordar si, de algún modo, no lo hago "desde la religión" 
Uno de esos capítulos es, para Aranguren, el de la solidaridad, a la que considera wheredera de la fraternidad cristiana». $Y$ es que Aranguren defendió siempre la apertura de la ética a la religión. Hace muchos años, escribio: «Pero toda existencia bien compuesta y templada tiene que ser, a la par, religiosa y moral. El esfuerzo ético, rectamente cumplido, se abre necesariamente a la religiosidad, termina por desembocar en ella [...] Y, por su parte, la actitud religiosa fructifica en accion moral, en buenas obras». ${ }^{36}$ Llega incluso a afirmar" "Ningún "contenido" (ético) puede tener validez universal si no está sustentado en Dios y por Diosw. ${ }^{37}$

Probablemente, Aranguren matizaría hoy estas afirmaciones. Pero creo que continuaría defendiendo la apertura de la ética a la religión. Lo hago constar para que no quede la impresión de que no hay más posibilidad que el triunfo de la ética sobre la religion o el de la religión sobre la ética.

Esta apertura no significa que la ética y la religión terminen por identificarse. Es cierto que, probablemente, no ha existido religión que no haya predicado a sus fieles: haz el bien y evita el mal. Todas dedican grandes espacios a la moral de sus adeptos. Casi todas poseen catálogos de preceptos morales: no matar, no robar, no mentir, no cometer adulterio... Todas se atienen a la regla de oro: «trata a los demás como desees que te traten a tin. El rabino Hillel condensaba lo nuclear de todas las religiones en una formula tan simple como grandiosa: "Sé bueno, hijo mío" ${ }^{38}$

Pero, no todo en la religión es moralidad. La fenomenología de la religión insiste con energía en este punto. La actitud religiosa tiene que ver con el misterio, con la adoración, con la alabanza, con el sometimiento. $R$. Otto dice que culmina en un «encuentro vivencial con lo sagrado". Tiene razón $F$. Savater cuando escribe: «Lo inefable, lo impensable, lo refractario a toda justificación inteligible puede tener su arrobo y su secreto júbilo pero desde luego no forma parte de la reflexión moral s.39

La apertura de la ética a la religión tampoco significa que la ética no sepa caminar sola a la hora de determinar los valores. La experiencia muestra lo contrario. Las grandes conquistas éticas de la Modernidad en el ámbito de los derechos humanos se lograron, con frecuencia, a pesar de la oposición frontal de la religión. La ética no depende de la religión. Podrá, eso sí, ser sensible a los impulsos válidos que ésta le ofrezca. La historia muestra que se ha dado una mutua fecundación. El cristianismo, ya lo dijimos, ha sido la matriz axiologica de Occidente. Pero, a su vez, la religión cristiana heredó los grandes temas y los grandes impulsos éticos de las filosofías que le precedieron, sobre todo de Platón y Aristóteles..$^{40} \mathrm{La}$ autonomía de la moral no puede significar que ésta se encierre en un espléndido aislamiento. Debe, más bien, recibir agradecida cualquier ayuda válida que se le brinde. Por lo demás, la moral autónoma, tal como la concibió Kant, será siempre más una meta que una conquista. El mismo 
Kant admitió que tal vez no hubo nunca nadie que ajustase su conducta a la pura norma autónoma. Tal autonomía pertenece al reino del deber ser, pero es posible que no se haya plasmado nunca. Y es que la moral es asunto del sujeto. Y éste, más que autonomo, parece condicionado y bien condicionado. El margen de libertad y autonomía del sujeto se estrecha cada vez más. El mandato kantiano de pensar por cuenta propia, sin acudir a tutelas ajenas, se topa con importantes zancadillas. Ni el más acendrado voluntarista alcanzará esa meta. Un mundo plural, agobiado de contrastes y sometido a un vértigo informativo, lo impide. El temor de Unamuno a que le carrebataran su yo» cobra inusitada actualidad.

La apertura de la ética a la religión no significa, por ultimo, que la ética pida a la religión que le preste su Dios para lograr así una fundamentación inconcusa de sus normas. Ya vimos que muchos contemporáneos nuestros renuncian a esta teonomía. La ética parece haberse resignado a vivir sin una fundamentación fuerte. Tal vez, pero no estoy seguro, la grandeza de la ética consista precisamente en que, como tantas otras parcelas importantes de la vida, no puede "probar» ni exhibir los cimientos sobre los que se asienta. Es posible «demostrar» la calidad del coche que se acaba de comprar o la solidez y consistencia del puente que se termina de construir; pero, paradójicamente, se nos escurre siempre lo más necesario, aquello de lo que más dependemos, lo más genuinamente humano. Hace años, N. Lohfink escribió: «El que exige que la resurrección de Jesús le sea demostrada exactamente comete un trágico error». Quería decir que la rebaja de categoría, que la equipara con el mundo de los objetos susceptibles de prueba y control, ¿No valdría lo mismo para la fundamentación de la ética? Pero tal vez estoy haciendo de la necesidad virtud... En todo caso, hace siglos que la ética renunció a una fundamentación religiosa. Desde entonces husmea en la inmanencia buscando en ella su soporte último. Su fundamentación no es ya trascendente, sino trascendental. Victoria Camps ve así nuestro tema: «El fundarnento de la ética está en el sentimiento y en la razón porque está en el lenguaje, un lenguaje que recoge y conserva la memoria ética de la humanidad. Y esa memoria nos proporciona el criterio del bien y del mal".4 Dios, afirma V. Camps - citando a Bernard Williams- "podría ser el fundamento de la moral, si lo conociéramos". ${ }^{42}$ Ahí radica el problema: ni la ética ni la religión conocen a Dios. Con una diferencia: la ética siempre podrá refugiarse en una ya larga tradición de «antropocentrismo ético» (J. Muguerza). Pero ¿qué hará la religión cuando se le eclipse Dios? Lo tiene algo peor que la ética.

¿Qué significa, entonces, la apertura de la ética a la religión? J. Sádaba afirma que "no es ningún ataque a la ética ponerla en contacto con la religión cuando aquella se plantea el sentido del hombre todo ${ }^{43}$ Cuando está en juego lo que nadie puede garantizar, la esperanza de los humanos, la ética y la religión aúnan sus esfuerzos. 
Ya al comienzo de estas páginas evoqué el desigual ritmo con el que la ética y la religión se aproximan a la esperanza: más sobria la ética, más decidida la religión. Vale la pena profundizar algo más en esta relación.

$Y$, probablemente, pocos lo han hecho con tanto dramatismo como W. Benjamin. ${ }^{44}$ Su ángel de la historia desearia edespertar a los muertos y recomponer lo despedazado». Pero no puede. Para hacerlo tendría que pedir ayuda a la tradición bíblica. Es ella la que, durante siglos, gestion6 los anhelos y esperanzas de la humanidad. Pero Benjamin no cree que esa tradición pueda hacer realidad lo que promete. Con todo, en diálogo con Horkheimer, se resiste a admitir que las víctimas carezcan por completo de futuro. Quiere seguir alentando una "débil esperanza mesiánica». Para ello, no rehúsa una tenue alianza parcial con el kenano jorobado», con la teología. ${ }^{45}$ No le importa que los ilustrados la consideren "pequeña y feas. 46

Al hilo del melancólico discurso benjaminiano, me pregunto: ¿no podría la religión, ese senano jorobado" - hoy posiblemente más ujorobado" que en los días de Benjamin- ayudar a la ética a ganar algunas causas? Ante el problema del pasado irredento, la ética se declara incompetente. En su arsenal de estrategias no hay ninguna aplicable al caso. Para ella, ese pasado está clausurado. La religión, en cambio, lo declara abierto. Se niega a archivar las causas de las víctimas. Sabe que ahí existen derechos pendientes y mantiene abiertos sus expedientes. Frente a la sobriedad ética, la religión aventura la esperanza.

Pero también el tema de la "sobriedad ética", del que tanto venimos hablando, merece una matización. No toda ética es igualmente sobria. Existe, es cierto, una ética de la inmediatez que no se sobrecarga con preguntas que carecen de respuesta. Es una ética decorosa que prescinde de las víctimas del pasado y concentra todas sus energías en ahorrar nuevos mártires al presente. Se declara incompetente en temas de esperanza para los injustamente sacrificados. Lo suyo es lidiar con el presente. Es un intento realista de favorecer el equilibrio, la convivencia y el diálogo entre los humanos. Aspira a una comunidad ideal de comunicación. Preconiza una justa distribución de la cultura y de los bienes sociales y materiales disponibles. Intenta que lo que hay alcance a todos. No es, ni mucho menos, una ética chata. Busca la utopía de la justicia como revulsivo permanente. No olvida ancestrales esperanzas de libertad, igualdad y fraternidad. Pero, eso sí, no se sobrecarga con la hipoteca de un pasado injusto por el que nada cree poder hacer. Alcanza, así, un alto grado de sobriedad.

Menos sobrio es el discurso ético que extiende la solidaridad al pasado. Es una ética que se deja acuciar por la memoria histórica. Vuelve su mirada, con inevitable desasosiego, hacia todo lo que le precedió. No lucha sólo por la mejor configuración del presente, sino que pregunta insistentemente por los ya-no-presentes. Intenta renegociar sus causas perdidas, in- 
troducir sentido donde no lo hubo. Le gustaría que nadie quedase sin compensación. Es una ética atenta a lo que nos llega de lejos. Además de actuar sobre el presente, medita sobre el pasado.

Y ésta es la ética que puede sellar alianzas con la religión. No, simplemente, para recordar a las víctimas. La ética que acabo de evocar posee una capacidad anamnética. No necesita pedirla prestada a la religión. Ella sabe alentar la cultura del recuerdo. Esta ética no es olvidadiza. Podrá, eso sí, reforzar su memoria en contacto con tradiciones religiosas que se decantan apasionadamente por mantener vivo el recuerdo de los mártires de la historia. Pero, incluso sin esta subvención, la ética sabe mantener encendida la mecha del recuerdo.

La alianza entre ética y religión alcanza su punto culminante en otro ámbito. Karl Rahner solía decir que el hombre se tomará siempre a sí mismo lo suficientemente en serio como para no renunciar a un futuro absoluto. En diálogo con otras cosmovisiones, más recatadas en lo referente a la esperanza, Rahner insistio siempre en dos axiomas de su teología: la esencial determinación esperanzada del hombre y la respuesta escatológica que el cristianismo ofrece a esa condición esperanzada de los humanos.

La cuestión central, en temas de esperanza, será siempre saber si hay algo que esperar. Es aquí donde la ética conoce su máxima sobriedad. Ella no sabe si hay algo que esperar. Eso sí: siente "anhelo» por la no frustración definitiva de lo constitutivamente deseado. Entre paréntesis: tampoco aquí convendría generalizar. Puede haber quien no desee más futuro que la liberación del presente. Pero no parece gratuito suponer, al menos desde nuestra tradición occidental, que el hombre no hace ascos a un posible futuro escenario sin víctimas ni verdugos. ${ }^{47} \mathrm{Y}$ es ahí donde hombres como W. Benjamin y $M$, Horkheimer consideraron inevitable, y no degradante, un cierto aterrizaje en la teología. El rechazo, por principio, de todo atisbo teológico les pareció podría rozar la banalidad. Opinión que compartía ampliamente $\mathrm{E}$. Bloch. La sola banalidad, afirmaba el autor de El principio de esperanza, no es ninguna liberación. Eso sí: sin abandonar nunca la sobriedad. Horkheimer dejo claro que «el conocimiento consciente del desamparo, de nuestra finitud, no se puede considerar como prueba de la existencia de Dios, sino que tan sólo puede producir la esperanza de que exista un absoluto positivon. ${ }^{48}$ Pero consideraba que, incluso con esta precariedad, "la teología está detrás de todo actuar realmente humanos.49 $\mathrm{Y}$ Adorno dejó escrito que «el pensamiento que no se decapita, desemboca en la trascendencia; su meta sería la idea de una constitución del mundo en la que no sólo quedara erradicado el sufrimiento establecido, sino incluso fuese revocado el que ocurrió irrevocablementes. ${ }^{50}$ Pero, el mismo Adorno escribi6: "La negatividad absoluta es previsible y ya no sorprende a nadie».51 De nuevo la sobriedad.

Probablemente, estos hombres fueron conscientes de que la esperanza 
se ha legitimado religiosamente a lo largo de la historia de la humanidad. De ahí que lo mejor de nuestra tradición filosófica actual siga encontrando un hueco a la religión. Es el caso de Habermas: «Mientras el lenguaje religioso sea portador de contenidos semánticos que resultan irrenunciables, pero que se sustraen (¿por el momento?) a la capacidad de expresión del lenguaje filosófico y que aguardan aún a ser traducidos al medio de la argumentación racional, la filosofía, incluso en su forma postmetafísica, no podrá ni sustituir ni eliminar la religión».52

Pero, como es bien sabido, el intento más logrado por arrancar a la ética y la religión lo mejor de sí mismas en favor del hombre lo realizó Kant. ${ }^{53}$ Kant no se resignó a que la moralidad nunca se encuentre con la felicidad en este mundo. En vista de ello les concertó una cita en otra vida. Postuló la inmortalidad como escenario propicio para que el hombre alcance en ella la felicidad de la que se ha hecho digno al actuar moralmente. Kant sitúa en un más allá lo que el más acá le niega. Es su forma de "solucionar" la antinomia entre deber y felicidad. Adorno llega a afirmar que el postulado de la inmortalidad kantiano "condena lo establecido por insufrible» y se abre al "ansia de salvar". Adorno continúa: «Si la razón kantiana se siente impulsada a esperar contra la razón es porque no hay mejora en este mundo que alcance a hacer justicia a los muertos, porque ninguna mejora afectaría a la injusticia de la muerte». ${ }^{54} \mathrm{El}$ secreto de la filosofía kantiana, concluye Adorno, ues la imposibilidad de pensar la desesperación». ${ }^{55}$ No sé si el término "desesperación" es aplicable a Kant. Sospecho que no. Pero, lo cierto es que, después de dedicar tantas energías a trazar fronteras, Kant se vio obligado a relativizarlas. Por supuesto: sin cruzar nunca la línea que separa el postulado de la afirmacion. La afirmación kantiana de Dios es indirecta. Kant pone el acento en el sombrio panorama que se seguiría de la no existencia de Dios y la inmortalidad: se resquebrajaría la fundamentación de la moral, se ensombrecería la esperanza de los humanos y quedarían mermadas las posibilidades del término "sentido". Fue todo esto lo que le impulsó a vincular estrechamente los términos "fe" y uracionalidad". Desde su "fe racional", no desde el "saber», Kant afirmó la condición de posibilidad de la no frustración radical, es decir, de Dios y la inmortalidad. Como tan escueta y magistralmente recuerda Aranguren, la existencia de Dios, en Kant, «debe ser admitida, no para la moralidad, sino por la moralidad».$^{56}$ La moralidad, lo sabemos, es autónoma. Anda sola. Pero, su vinculación con la felicidad, y la amarga constatación de que este mundo no parece campo abonado para esa felicidad, condujo a Kant a postular escenarios más benévolos.

No es difícil descubrir la impronta kantiana en todos los discursos éticos que han venido después. Especialmente llamativo es su influjo sobre M. Horkheimer, a quien repetidas veces nos hemos referido. Afirmaba Horkheimer que la filosofía se preocupa de que "no nos timen". Hacia esa 
meta se orientaba la fe racional o filosófica que Kant, Horkheimer y muchos otros defendieron.

Quien sí nos "timará", si nos descuidamos, es Kolakowski. Su intento de resucitar la convicción de Dostoievski, «si Dios no existe, todo está permitido», suscita preocupación. Es la expresión máxima de un nuevo canto a la heteronomía. Imagino que lo de Kolakowski no hubiera ocasionado grandes descalabros en la Edad Media, época teocéntrica por excelencia. Pero, nuestros días, como recordó $\mathrm{M}$. Buber, están conociendo el eclipse de Dios. Y no parece conveniente resignarse a que la decadencia de la convicción térnoma arrase con todo. Kolakowski entiende su afirmación «no sólo como regla moral, sino también como principio,epistemológico. Esto significa que sólo si existe un espíritu absoluto es legítimo hablar de "verdad" o suponer que nuestro entendimiento puede captarlan. ${ }^{57}$ En un mundo en el que, si existe Dios, las vías de acceso a él son tan exiguas, el alegato teocéntrico de Kolakowski nos deja en una insoportable precariedad ética y epistemológica. No veo necesario pagar este tardío y anacrónico tributo a un teocentrismo inexistente. Hay algo, sin embargo, en lo que sí estoy de acuerdo con Kolakowski: una suspensión de lo teológico no ayudaría a mitigar ningún dolor. Sólo que yo añadiría: una absolutización tampoco.

Llegamos, así, al final de este trabajo. No he defendido ninguna tesis original ni brillante. La constatación de que, en temas de esperanza, la ética es más sobria que la religión es bastante obvia y conocida. Mi trabajo sólo ha consistido en pasar algunas hojas de ese monumental álbum familiar ético-religioso que forma ya parte de nuestra herencia cultural. Por supuesto, no he recorrido todas las instantáneas. Ahí queda, sin ir más lejos, el noble proyecto ético de Javier Muguerza. Después de recorrer un largo camino de la mano de Kant, Horkheimer, Benjamin y otros pensadores aludidos en este trabajo, Muguerza parece aventajar a todos en sobriedad y recomienda a la ética que se afirme aal margen de cualquier perspectiva de éxito, incluidas las siempre respetables ilusiones teológicas relativas a una recompensa final tras nuestros sufrimientos en un mundo y una historia sin probables alternativas trascendentes». .8 Estamos, sin duda, ante un discurso ético tan intenso como sobrio. Y ahí queda también, sin el espacio que hubiera merecido, la reflexión ética de José Gómez Caffarena, humanista y cristiana. La opción por un sentido final, bellamente expresada en lo que Gómez Caffarena llama "vivencias de fundamento" y "vivencias de esperanza* le lleva a postular un fundamento último de la realidad. ${ }^{59}$ No se resigna a que el deseo constitutivos del hombre quede radicalmente frustrado. De ahí el bello final de su libro, El teísmo moral de Kant: «En su secular esfuerzo moral, y pese a sus fracasos, la Humanidad se merece que no sea fallida su esperanza: se merece que exista Dios».60 Estamos ante una aspiración tan noble como indefensa. Caffarena, ayuda- 
do por su inquebrantable fe cristiana, conduce el dinamismo postulatorio kantiano a su máxima expresión. Un dinamismo que $B$. Russell se encargó de atemperar: es — decía - como si compras una caja de naranjas, ves que la primera capa está podrida y dices: las de abajo tienen que estar sanas para que se equilibre la situación. No es, ciertamente, ningưn prodigio de profundidad argumentativa, pero, como aviso, no está mal. Con todo, uno casi prefiere quedarse con Unamuno, que postulaba la inmortalidad para que «nuestro trabajado linaje humano sea algo más que una fatídica procesión de fantasmas que van de la nada a la nada».

La ética y la religión anhelan una especie de imposible necesario: que, como decía Bloch, la última música que escuchemos no sean las paletadas de tierra que alguien arrojará sobre nuestro ataúd. La religión espera, "contra toda esperanza», otro cielo y otra tierra. La ética interroga pertinazmente a la religión sobre el fundamento de esa esperanza. A su vez, la religión, después de ofrecer tenues razones, remite al misterio, al silencio. $\mathrm{Y}$, como la ética también sabe de silencios, ambas se encuentran en una especie de gesticulación impotente. La ética de la resistencia se da la mano con la religión de la perseverancia. Una gran tarea compartida se abre ante ellas: aliviar el sufrimiento de los humanos y soñar, como quería Benjamin, con que, un día, no sabemos cuándo ni cómo, se dé «una cita secreta entre las generaciones que fueron y la nuestra».

\section{NOTAS}

1. H. Cohen, Der Begriff der Religion in System der Philosophie, Giessen, 1915.

2. Véase, por ejemplo, J. Schmitz, Filosofía de la religión, Barcelona, Herder, 1987, p. 27; J. Hessen, Religionsphilosophie, vol, II, Münich/Basilea, Emst Reinhardt, 1955, pp. 39 y ss.

3. H. Cohen, op. cit., p. 42, n. 18.

4. G.F. Fichte, Samtliche Werke (ed. de I.H. Fichte, su hijo) vol, II, Berlín, 1845-1846, p. 226.

5. J. Sádada, «La filosofia de la religión en la Universidad española», en J. Gómez Caffarena y J.M. Mardones (eds.), Estudiar la religión. Materiales para una filosofía de la religión III. Barcelona, Anthropos, 1993, p. 149.

6. J.L. López Aranguren, Ética, Madrid, Alianza, 1986, pp. 103-133. Aranguren, a su vez. tiene en cuenta a J. Hessen, op. cit., pp. 39-59.

7. J. Martín Velasco, «Religión y moral», en $\mathbf{M}$. Vidal (ed.), Conceptos fundamentales de ética teológica, Madrid, Trotta, 1992, pp. 185-203. Véase también H. Delfor Mandrioni, «Religión, ética y estétican, en J. Gómez Caffarena (ed.), Religión, Madrid, Trotta, 1993, pp. 195209. El mismo tema que abordo aquí lo estudia, en valiosa y apretada síntesis, Carlos Gómez Sánchez, "Problemas éticos en relación con la religión», en O. Guariglia (ed.), Problemas de ética, Madrid, Trotta (de próxima aparición).

8. N. Hartmann, Ethik, Berlín, 1926, pp. 737 y ss.

9. Para una amplia confrontación con la postura de N. Hartmann véase J. Hessen, op. cit.. pp. 44-51.

10. Véase Martín Velasco, op. cit., p. 190, n. 14.

11. Ibid.

12. J.L. López Aranguren, op, cit., p. 105. 
13. Ibid

14. Es algo que ha visto muy bien $\mathrm{H}$. Küng, Proyecto de una ética mundial, Madrid, Trotta, 1991.

15. Ibid., p. 55.

16. P. Tillich, Das religiose Fundament des moralixchen Handelns. Schriften zur Ethik und zum Menschenbild. Gesammelte Werke, vol. III, Stuttgart, Evangelisches Verlagswerk, 1965, p. 14.

17. Ibid., p. 15.

18. Ibid., pp. 13-56. Veanse, especialmente, las páginas $16,26,27,35,40$ y 55 . W. Pannenberg y $G$. Ebeling mantuvieron, en los años sesenta, una notable controversia sobre la relación entre ética y teología. Simplificando mucho, se puede afirmar que Ebeling, siguiendo a Hermann y Ritschl, defendió una "fundamentación ética de la teología». Pannenberg, en cambio, se inclinó por una sfundamentación teologica de la éticas. Argumentaba Pannenberg que la realidad de Dios no puede depender de su relevancia ética. Al contrario: para que Dios tenga relevancia ética debemos, primero, estar seguros de que existe. Ebeling, por su parte, argüía que no es posible el acceso a Dios, objeto de fe, sin tener en cuenta la relevancia ética de esa fe. Pannenberg pensó que Ebeling recurría a la wevidencia del fenómeno ético» para lograr «un terreno libre de tormentas» desde el que construír un argumento dogmático en favor de la realidad de Dios. La tesis de Pannenberg era que la ética se ha vuelto tan problemática como la religión o la metafísica. De ahi que no sea un soporte suficientemente sólido para acceder a la realidad de Dios. Es mejor no aislar el terna ético e integrarlo en una concepción abarcadora de la realidad y de la historia. Solo el final de esa realidad y de esa historia arrojara luz definitiva sobre la realidad de Dios; pero nunca una sola dimensión de la realidad - la ética- por muy evidente que le parezca a Ebeling. Véase G. Ebeling, Wort und Glaube II, Tubinga, J.C.B. Mohr, 1969, pp. 1-15; W. Pannenberg, Ethik tnd Ekklesiologie, Gotinga, Vandenhoeck \& Ruprecht, 1977, pp. 41-69.

19. J.L. Lopez Aranguren, op. cit., p. 105; id., Catolicismo y protestantismo como formas de existencia, Madrid, Alianza, 1980, pp. 45-77.

20. S. Kierkegaand, Temor y temblor, Madrid, Tecnos, 1987.

21. G.F. Fichte, Werke (ed. Medicus), vol. III, p. 130.

22. A. Cortina, Etica mínima. Intraducción a la filosofía präctica, Madrid, Tecnos, $1992^{3}$. Esta obra, ágil y profunda, aborda detenidamente la relación entre ética y religión.

23. A. Camus, Lhomme revolte, 1951.

24. Sigue siendo de interés la lectura de $\mathbf{H}$. de Lubac, El drama del humanismo ateo, Madrid, Encuentro, 1990.

25. Véase, sobre todo, E. Bloch, El principio esperanza, vol, III, Madrid, Aguilar, 1980; id., El ateismo en el cristianismo, Madrid, Taurus, 1983. La relación de Bloch con la religion ha sido muy bien analizada en la reciente obra de J.J. Tamayo-Acosta, Religion, razón y esperanza. El pensamiento de Emst Bloch, Estella, Verbo Divino, 1992. Para un estudio comparativo entre Bloch y Horkheimer véase el excelente trabajo de J. Muguerza, wÉtica y teología después de la muerte de Dios", Enrahonar, 2 (1981), pp. 99-112.

26. Citado por H. Küng, ¿Existe Dios?, Madrid, Cristiandad, 1979, p. 636.

27. F. Nietzsche, Creprisculo de los idolos, Madrid, Alianza, 1986, p. 112.

28. F. Nietzsche, El anticristo, Madrid, Alianza, 1985, pp. 29 y ss.

29. Ibid., p. 109.

30. R.B. Braithwaite, An empiricist view of the nature of religious belief, Cambridge, 1955 , p. 10.

31. R. Hepbum, Christianity and Paradox, Londres, 1958, p. 192.

32. Véase el genial estudio de K. Barth, Die protestantische Theologie in 19. Jahrhundert, vol. 2, Hamburgo, Siebenstem Taschenbuch, 1975, pp. 564-571.

33. Son aspectos que destaca $R$. Bultmann en su introducción a la obra de A. von Harnack, Das Wesen des Christentums, Hamburgo, Siebenstem Taschenbuch, 1964, pp. 9 y ss.

34. Para una historia de la teología dialectica sigue siendo atractiva la obra de H. Zahrnt, 
A vueltas con Dios. La teologia protestante en el siglo XX, Zaragoza, Hechos y dichos, 1972, esp. pp. 13-77.

35. E. López-Aranguren, J. Muguerza, J.M. Valverde (eds.), Retrato de José Luis L Aranguren, Madrid, Cínculo de Lectores, 1993, p. 87.

36. J.L. Lopez Aranguren, Etica, op. cit., p. 104.

37. Ibid, p. 119.

38. J. Martín Velasco, op. cit., p. 185.

39. F. Savater, Schopenhauer. La abolición del egoismo, Barcelona, Montesinos, 1986, p. 11.

40. Véase J. Gómez Caffarena, Qué aporta el cristianismo a la ética, Madrid, Fundación SM, 1991. Es un estudio ejemplar que completa y prolonga un trabajo anterior de Caffarena: El cristunismo y la filosofia moral cristiana, en V. Camps (ed.): Historia de la ética. 1. De los griegos al renacimiento, Barcelona, Crítica, 1988, pp. 282-344.

41. V. Camps, la imaginación ética. Nueva edición, Barcelona, Ariel, 1991, p. Xv.

42. Ibid. p. 14. El tema de la fundamentación de la ética lo trata también ampliamente A. Cortina, op. cit., pp. 77-139. Véase, de la misma autora, Ética sin moral, Madrid, Tecnos, 1990, pp. 98-119.

43. J. Sádada, op. cit, p. 148.

44. Sobre W. Benjamin hay páginas muy valiosas en Reyes Mate, La razón de los vencidos, Barcelona, Anthropos, 1991. También Ana Lucas está dedicando estudios importantes a la figura de W. Benjamin. Véase su libro, El trasfondo barroco de lo modemo, Madrid, Cuadernos de la UNED, 1992.

45. W. Benjamin, Discursos intemampidos I, Madrid, Taurus, 1989, p. 177.

46. Ibid.

47. Son conocidas las formulaciones de $M$. Horkheimer en $A$ la busqueda del sentido, Salamanca, Sígueme, 1976. Sobre Horkheimer aparecerá próximamente la traducción castellana de la obra de J.J. Sánchez, Wider die Logik der Geschichte. Religionskcritik und die Frage nach Gott im Werk Max Horkheimers, Zurich-Einsiedeln-Colonia, Benzinger, 1980. La traducción de esta importante obra incorpora también la investigación sobre Horkheimer, posterior a 1980.

48. Ibid, p. 103.

49. lbid, p. 105.

50. Th. W. Adomo, Dialéctica negativa, Madrid, Taurus, 1989, p. 401.

51. lbid., p. 362.

52. J. Habermas, Pensamiento postmetaffsico, Madrid, Taurus, 1990, pp. 62 ss. Para una visión más completa de la postura de Habermas frente a la religión, véanse sus dos estudios: "Zu Max Horkheimers Satz: "Einen unbedingten Sinn zu retten ohne Gott, ist eitel" y "Exkurs: Transzendenz von innen, Transzendenz ins Diesseits", ambos publicados en J. Habermas, Texte und Kontexte, Francfort, Suhrkamp, 1991, pp. 110-156.

53. Sobre la relación entre moral y religión en Kant es fundamental el estudio de J. Gómez Caffarena, El tetsmo moral de Kant, Madrid, Cristiandad, 1983. Este libro merecio una elogiosa y cálida recensión de J. Muguerza, Desde la perplejidad, Madrid, FCE, 1990, pp. 591610. Véase también el lúcido texto de $\mathrm{R}$. Rodríguez Aramayo, Crítica de la razón zcrónica. Estudios en tomo a las aporias morales de Kant, Madrid, Tecnos, 1992. Al tema de la esperanza en Kant ha dedicado J. Muguerza su ensayo «Kant y el sueño de la razón», en $C$. Thiebaut (ed.), La herencia ética de la llustración, Barcelona, Critica, 1991, pp. 9-36.

54. Th.W. Adomo, op. cit, p. 384.

55. Tbid., p. 385.

56. J.L. López Aranguren, Etica, p. 118.

57. L. Kolakowski, Falls es keinen Gott gibt, Múnich, Piper, 1982, p. 74.

58. J. Muguerza, Desde la perplejidad, op. cit, p. 609.

59. J. Gómez Caffarena, Razón y Dios, Madrid, Fundación SM, 1985, pp. 55 ss.

60. J. Gómez Caffarenn, El teísmo moral de Kant, op. cit., p. 247. 